\title{
The Significance of Bone Marrow Involvement in Aggressive Lymphomas: A Retrospective Comparison of Clinical Outcomes between Peripheral T Cell Lymphoma and Diffuse Large B Cell Lymphoma in China
}

\author{
Shuhua Yia Gang An ${ }^{a}$ Junyuan Qi ${ }^{a}$ Dehui Zou ${ }^{a} \quad$ Yaozhong Zhao ${ }^{a}$ \\ Peihong Zhang ${ }^{a}$ Huishu Chen ${ }^{a}$ Jun Wang ${ }^{b}$ Lugui Qiu $^{a}$ \\ a Institute of Hematology and Blood Diseases Hospital, Chinese Academy of Medical Sciences and Peking Union \\ Medical College (CAMS and PUMC), Tianjin, China; ${ }^{b}$ Department of Pathology and Laboratory Medicine, \\ Loma Linda University Medical Center, Loma Linda, Calif., USA
}

\section{Key Words}

Diffuse large B cell lymphoma • Immunophenotype $\cdot$

Peripheral T cell lymphomas · Prognosis

\begin{abstract}
Background: Peripheral T cell lymphomas (PTCL) have been demonstrated to have a poorer prognosis than diffuse large $B$ cell lymphoma (DLBCL) due to a high frequency of bone marrow involvement (BMI). However, the clinical characteristics of PTCL with BMI have not been fully described, and the clinical outcomes of PTCL with BMI and DLBCL with BMI have not been well compared. Methods: The clinical characteristics and survival of 25 nodal PTCL cases with BMI and 42 DLBCL cases with BMI were compared. Results: Most of the PTCL patients with BMI had lymphadenopathy (88\%), B symptoms (76\%), an elevated LDH level (68\%), anemia (64\%), splenomegaly (60\%), and a poor performance status (52\%). Except for the differences of lymphadenopathy and thrombocytopenia between PTCL with BMI and DLBCL with BMI, similarities in gender, age, hepatomegaly, splenomegaly, a bulky mass, B symptoms, elevated LDH, $\geq 2$ extranodal sites,
\end{abstract}

ECOG scores $\geq 2$, anemia, and international prognostic index (IPI) and age-adjusted IPI scores were observed between the 2 groups. The 2 groups also had similar 3-year overall survival ( 25.8 vs. $30.0 \%, p=0.846$ ) and progressive-free survival (21.3 vs. $25.2 \%, p=0.815$ ) rates. Conclusions: $\mathrm{PTCL}$ with BMI have a similar aggressive course and poor survival compared to DLBCL with BMI. Thus, the immunophenotype of either $T$ or $B$ lineage may not be a crucial prognostic indicator of survival for these 2 aggressive lymphomas.

Copyright $\odot 2010$ S. Karger AG, Basel

\section{Introduction}

Peripheral T cell lymphomas (PTCLs) represent a heterogeneous group of disorders in the World Health Organization (WHO) classification [1], including angioimmunoblastic T cell lymphoma (AITL), PTCL unspecified (PTCL-u), and anaplastic large cell lymphoma (ALCL), which are mainly nodal PTCLs. Despite aggressive therapy, the prognosis of PTCLs is dismal, with 5-year overall survival (OS) ranges between 25 and $45 \%$ and more than

\section{KARGER}

Fax +4161306 1234 E-Mail karger@karger.ch www.karger.com (c) 2010 S. Karger AG, Basel

$0001-5792 / 10 / 1244-0239 \$ 26.00 / 0$

Accessible online at:

www.karger.com/aha
288 Nanjing Road, Heping District

Tianjin 300020 (China)

Tel. +86 222390 9172, Fax +86222721 8738

E-Maildrqiu99@medmail.com.cn 
Table 1. Comparison of the primary clinical characteristics and therapeutic regimens between PTCL and DLBCL

\begin{tabular}{|c|c|c|c|}
\hline Characteristics & $\begin{array}{l}\text { DLBCL } \\
(\mathrm{n}=42)\end{array}$ & $\begin{array}{l}\text { PTCL } \\
(\mathrm{n}=25)\end{array}$ & $\mathrm{p}$ \\
\hline Age $>60$ years & $6(14.3)$ & $3(12.0)$ & $1.000^{\mathrm{a}}$ \\
\hline Male gender & $24(57.1)$ & $17(68.0)$ & $0.378^{\mathrm{b}}$ \\
\hline Lymphadenopathy present & $26(61.9)$ & $22(88.0)$ & $0.022^{\mathrm{b}}$ \\
\hline Hepatomegaly present & $14(33.3)$ & $8(32.0)$ & $0.911^{\mathrm{b}}$ \\
\hline Splenomegaly present & $21(50.0)$ & $15(60.0)$ & $0.427^{\mathrm{b}}$ \\
\hline Bulky mass & $2(5.1)$ & $3(12.0)$ & $0.371^{\mathrm{a}}$ \\
\hline ECOG PS $\geq 2$ & $23(54.8)$ & $13(52.0)$ & $0.905^{\mathrm{b}}$ \\
\hline$\geq 2$ ENS involved & $5(11.9)$ & $8(32.0)$ & $0.059^{\mathrm{a}}$ \\
\hline B symptoms present & $30(71.4)$ & $19(76.0)$ & $0.683^{\mathrm{b}}$ \\
\hline Elevated LDH & $27(64.3)$ & $17(68.0)$ & $0.757^{\mathrm{b}}$ \\
\hline Hemoglobin $<11 \mathrm{~g} / \mathrm{dl}$ & $34(81.0)$ & $16(64.0)$ & $0.123^{\mathrm{b}}$ \\
\hline $\mathrm{PLT}<100 \times 10^{9} / 1$ & $24(57.1)$ & $7(28.0)$ & $0.021^{\mathrm{b}}$ \\
\hline $\mathrm{WBC}>10 \times 10^{9} / 1$ & $6(14.3)$ & $2(8.0)$ & $0.700^{\mathrm{a}}$ \\
\hline IPI score & & & $0.143^{\mathrm{b}}$ \\
\hline $0-1$ & $5(11.9)$ & $7(28.0)$ & \\
\hline 2 & $19(45.2)$ & $5(20.0)$ & \\
\hline 3 & $13(31.0)$ & $10(40.0)$ & \\
\hline $4-5$ & $5(11.9)$ & $3(12.0)$ & \\
\hline aaIPI score & & & $0.087^{b}$ \\
\hline 0 & 0 & 0 & \\
\hline 1 & $6(16.7)$ & $7(30.4)$ & \\
\hline 2 & $16(44.4)$ & $13(56.5)$ & \\
\hline 3 & $14(38.9)$ & $3(13.1)$ & \\
\hline Therapeutic regimens & & & $0.441^{b}$ \\
\hline CHOP regimen & $23(54.8)$ & $11(44.0)$ & \\
\hline Intensive chemotherapy & & & \\
\hline regimen & $15(35.7)$ & $9(36.0)$ & \\
\hline High-dose therapy plus ASCT & $4(9.5)$ & $5(20.0)$ & \\
\hline
\end{tabular}

Figures in parentheses are percentages. PTCL indicates peripheral T-cell lymphoma unspecified plus angioimmunoblastic T-cell lymphoma. ASCT = Autologous stem cell transplantation.

a Fisher's exact test.

${ }^{\mathrm{b}} \chi^{2}$ test.

half the patients dying of the disease [2-4]. In previous studies, it has been shown that PTCLs have a more aggressive clinical course and poorer prognosis than their B cell counterpart, i.e. diffuse large B cell lymphoma (DLBCL) [5-7]. This difference was partially attributed to the high percentage of bone marrow involvement (BMI) in PTCLs [6]. BMI was one of the poor prognostic markers in these disorders [8]. Although the clinical characteristics of DLBCL with BMI have been described, such as a poorer performance status (PS), more extranodal sites (ENS), and greater percentages of patients with elevated $\mathrm{LDH}$ than without $[9,10]$, the clinical characteristics of PTCLs with BMI have not been well explored, and it is unclear if these 2 diseases at a similar stage actually differ in terms of their clinical outcome.

Few studies have directly compared advanced stage DLBCL with PTCL, which is probably attributable to the rarity of PTCL as it accounts for only approximately $10 \%$ of all non-Hodgkin's lymphomas (NHL) encountered in the Western countries $[5,11]$ and about $25 \%$ of those in Asia $[12,13]$. Patients with PTCL with BMI were even fewer, i.e. only $6-30 \%$ of cases $[10,14-17]$. In this study, we took advantage of the higher prevalence of PTCL with BMI and DLBCL with BMI in our hospital and retrospectively analyzed the clinical characteristics and outcomes of consecutive patients with PTCL with BMI compared with those of patients with DLBCL with BMI. Because the prognosis of ALK + ALCL is better than that of nonALCL PTCL [17], ALCL cases were excluded from this study.

\section{Patients and Methods}

\section{Patient Population}

The population enrolled into this study comprised 21 patients with PTCL-u, 4 patients with AITL (PTCL), and 42 patients with DLBCL, all of whom were diagnosed and treated at the Institute of Hematology and Blood Diseases Hospital, Chinese Academy of Medical Sciences and Peking Union Medical College (CAMS and PUMC). Histologic sections from each patient were reviewed by 2 hematopathologists (H.C. and J.Q.) and the diagnoses were confirmed according to the WHO classification [1]. All bone marrow tissues evaluated in this study were obtained at the time of the initial staging procedure. Clinical staging was performed before the initial therapy according to the Ann Arbor system. The international prognostic index (IPI) and the age-adjusted IPI (aaIPI) were routinely evaluated in all of the aggressive NHL patients at diagnosis.

The following clinical features were analyzed as potential prognostic factors: age( $>60$ vs. $\leq 60$ years), gender, ECOG PS (scores $2-4$ vs. $0-1$ ), B symptoms (present or absent), LDH concentration (elevated vs. normal), hepatomegaly (present or absent), splenomegaly (present or absent), lymphadenopathy at diagnosis (present or absent), the number of ENS involved ( $\geq 2$ vs. $<2$ ) (excluding BMI), the presence or absence of bulky disease (maximal diameter $\geq 10 \mathrm{~cm}$ ), hemoglobin concentration, platelet number (PLT), white blood cell (WBC), IPI, and aaIPI. Hemoglobin, PLT, and WBC were converted into appropriate binary variables.

\section{Treatment}

As shown in table 1, eleven patients (44.0\%) in the PTCL group and 23 patients $(54.8 \%)$ in the DLBCL group received cyclophosphamide, doxorubicin, vincristine, and prednisone (CHOP) chemotherapy. Nine patients (36.0\%) in the PTCL group and 15 patients $(35.7 \%)$ in the DLBCL group received a third-generation chemotherapy regimen [e.g. ProMACE-CytaBOM (methotrexate, prednisone, doxorubicin, cyclophosphamide, etoposide, $c y-$ 
tosine arabinoside, bleomycin, and vincristine) or MACOP-B (doxorubicin, cyclophosphamide, vincristine, methotrexate, bleomycin, and prednisone)] or an even more intensive chemotherapy regimen such as HyperCVAD/MA (cyclophosphamide, doxorubicin, vincristine, prednisone, methotrexate, and cytarabine). These patients were defined as the intensive chemotherapy regimen group. The remaining 5 patients $(20 \%)$ in the PTCL group and 4 patients $(9.5 \%)$ in the DLBCL group were treated with highdose chemotherapy plus autologous stem cell transplantation. No radiotherapy was added in the treatment course.

\section{Assessment of Response}

The response was evaluated based on the International Workshop Criteria reported in 1999 [18]. OS was measured as the interval between the date of the initial treatment and the date of death and/or the last follow-up. Progression-free survival (PFS) was measured as the interval between the date of the initial treatment and the date of death from any cause or disease progression.

\section{Statistical Analysis}

Fisher's exact test or a $\chi^{2}$ test was used to determine statistically significant differences between the clinical characteristics of the 2 groups. A survival curve was constructed using the KaplanMeier method, prognostic features were evaluated using univariate analysis (logrank test), and the effects of potential prognostic variables on survival were assessed according to the Cox regression method. $\mathrm{p}<0.05$ was considered statistically significant. All calculations were performed using the SPSS statistical software package (version 13.0).

\section{Results}

\section{Clinical Characteristics}

The patients' ages ranged from 18 to 77 years (median 39 years) in the PTCL group and from 13 to 71 years (median 41 years) in the DLBCL group. The clinical characteristics of the patients are listed in table 1 . BMI of PTCL was found predominantly in males, with a male-to-female ratio of 2.1:1. Most patients (88.0\%) with PTCL with BMI had lymphadenopathy at diagnosis, while $76.0 \%$ had B symptoms, $68.0 \%$ had elevated LDH, $64.0 \%$ had anemia, $60.0 \%$ had splenomegaly, and $52.0 \%$ had scores $>1$ on the ECOG PS, indicating an aggressive clinical course. Compared with DLBCL, these 2 groups were similarly distributed with respect to gender, age, hepatomegaly, splenomegaly, a bulky mass, B symptoms, elevated LDH, ECOG PS $\geq 2, \geq 2$ ENS, hemoglobin $<11 \mathrm{~g} / \mathrm{dl}$, and WBC $>10 \times 10^{9} / 1$. The frequency of lymphadenopathy at diagnosis $(88.0 \%)$ was higher in the PTCL group $(\mathrm{p}=0.022)$, while the frequency of thrombocytopenia (57.1\%) was higher in the DLBCL group $(\mathrm{p}=0.021)$. Although there was a greater number of patients with unfavorable IPI scores in the PTCL group and a greater number of pa- tients with unfavorable aaIPI scores in DLBCL group, no statistically significant differences were found between the 2 groups $(\mathrm{p}=0.143$ and $\mathrm{p}=0.087$, respectively).

\section{Response and Survival}

There were no statistically significant differences between the 2 groups with respect to therapy regimens (table 1). The response to the initial treatment was as follows: among the patients with PTCL, 16 patients achieved complete response or complete response uncertain $(\mathrm{CR} / \mathrm{CRu})$ (64\%), 3 patients had a partial response (PR) (12\%), and 6 patients (24\%) had stable disease (SD) and progressive disease (PD). Among the patients with DLBCL, 21 patients achieved a CR/CRu (50\%), while 9 patients had a PR (21.4\%), and 12 patients had SD/PD (28.6\%). The CR/CRu rates and the overall response rates (CR/CRu plus $\mathrm{PR}$ ) between the 2 groups were similar $(\mathrm{p}=0.316$ and $\mathrm{p}=$ 0.780 , respectively).

After a median follow-up of 11 months (42 months for surviving patients), 49 patients died. The median followup for survivors was 35.5 months in patients with PTCL and 45 months in patients with DLBCL. As expected, the survival of this population was poor in general. The median OS and PFS of the 67 patients was $13.0 \pm 3.5$ months (95\% CI 6.2-19.8) and $11.0 \pm 3.0$ months (95\% CI 5.216.8); the expected 3-year OS and PFS rates were $26.8 \pm$ $5.7 \%$ and $23.9 \pm 5.5 \%$. The median OS was $13.0 \pm 4.3$ months (95\% CI 4.5-21.5) in the DLBCL group and 14.7 \pm 7.0 months (95\% CI 1.0-28.3) in the PTCL group, respectively. The median PFS was $11.0 \pm 3.7$ months (95\% CI 3.8-18.2) and $11.0 \pm 4.7$ months (95\% CI 1.8-20.2) in each group, respectively. As is shown in figures 1 and 2 , the 3-year OS and PFS rates were $30.0 \pm 7.3 \%$ and 25.8 $\pm 9.6 \%$ in the DLBCL group and $25.2 \pm 7.0 \%$ and 21.3 $\pm 9.1 \%$ in the PTCL group, respectively, with no statistically significant differences found between the 2 groups ( $\mathrm{p}=0.846$ and $\mathrm{p}=0.815$, respectively).

\section{Prognosis Analysis}

Univariate analysis revealed that the presence of splenomegaly, elevated LDH, anemia and thrombocytopenia were significant predictors of a reduced OS (table 2), and these factors plus $\mathrm{WBC}>10 \times 10^{9} / 1$ predicted an unfavorable PFS (table 3). Among these factors, only thrombocytopenia was observed more frequently in patients with DLBCL (table 1). Cox multivariate analysis was carried out based on factors that were positive in the univariate analysis. Only elevated LDH was an unfavorable predictor for OS and PFS, which was distributed equally in both groups. (table 2, 3). 


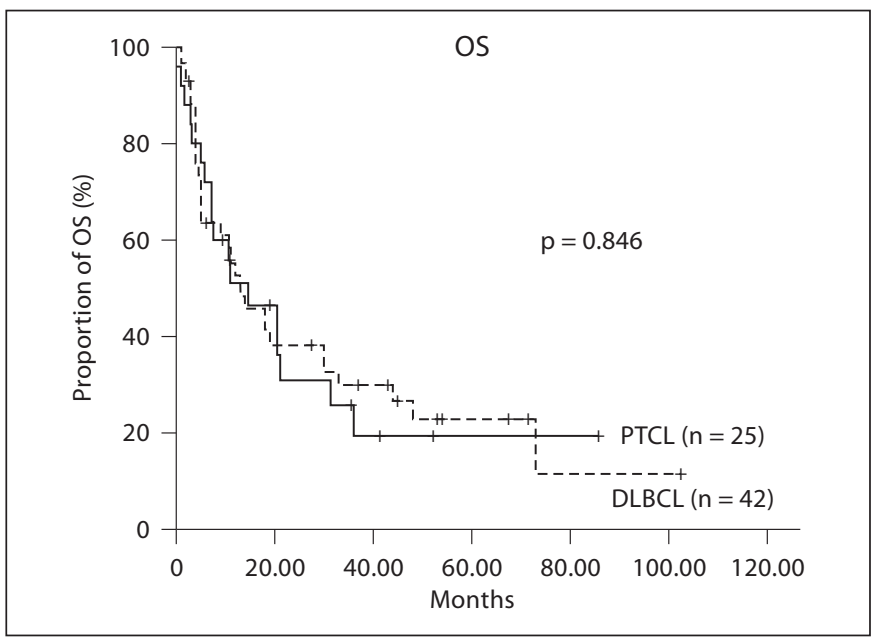

Fig. 1. OS curves of 25 PTCL patients with BMI and 42 DLBCL patients with BMI. No difference was found between the 2 groups $(\mathrm{p}=0.846)$.

Table 2. Risk factors for OS in 67 patients

\begin{tabular}{|c|c|c|c|}
\hline Variables & $\begin{array}{l}\text { Uni- } \\
\text { variate } \\
\mathrm{p}^{\mathrm{a}}\end{array}$ & $\begin{array}{l}\text { Multi- } \\
\text { variate } \\
\mathrm{p}^{\mathrm{b}}\end{array}$ & $\begin{array}{l}\mathrm{RR} \\
(95 \% \mathrm{CI})\end{array}$ \\
\hline Age (>60 vs. $\leq 60$ years) & 0.940 & & \\
\hline Gender (male vs. female) & 0.799 & & \\
\hline Lymphadenopathy (present vs. absent) & 0.866 & & \\
\hline Hepatomegaly (present vs. absent) & 0.164 & & \\
\hline Splenomegaly (present vs. absent) & 0.017 & 0.139 & \\
\hline Bulky mass (present vs. absent) & 0.800 & & \\
\hline ECOG PS (0-1 vs. $2-4)$ & 0.176 & & \\
\hline No. of ENS (0-2 vs. >2) & 0.158 & & \\
\hline B symptoms (present vs. absent) & 0.683 & & \\
\hline Elevated LDH (yes vs. no) & 0.002 & 0.034 & $\begin{array}{l}2.2 \\
(1.1-4.5)\end{array}$ \\
\hline Hemoglobin $(<11 \mathrm{~g} / \mathrm{dl}$ vs. $\geq 11 \mathrm{~g} / \mathrm{dl})$ & 0.041 & 0.946 & \\
\hline $\operatorname{PLT}\left(<100 \times 10^{9} / 1\right.$ vs. $\left.\geq 100 \times 10^{9} / 1\right)$ & 0.001 & 0.130 & \\
\hline WBC $\left(>10 \times 10^{9} / 1\right.$ vs. $\left.\leq 10 \times 10^{9} / 1\right)$ & 0.146 & & \\
\hline
\end{tabular}

Multivariate analysis was carried out based on factors that were positive in univariate analysis. $\mathrm{RR}=$ Relative risk; $\mathrm{CI}=$ confidence interval. ${ }^{\mathrm{a}}$ Logrank test. ${ }^{\mathrm{b}}$ Cox regression analysis.

\section{Discussion}

PTCLs are a heterogeneous group of neoplasms accounting for $7-10 \%$ of NHL in the Western countries compared to $20-30 \%$ of NHL in East Asia, including China [5, 11-13]. Patients often present with an advanced stage of the disease, and the neoplasms are characterized by wide-

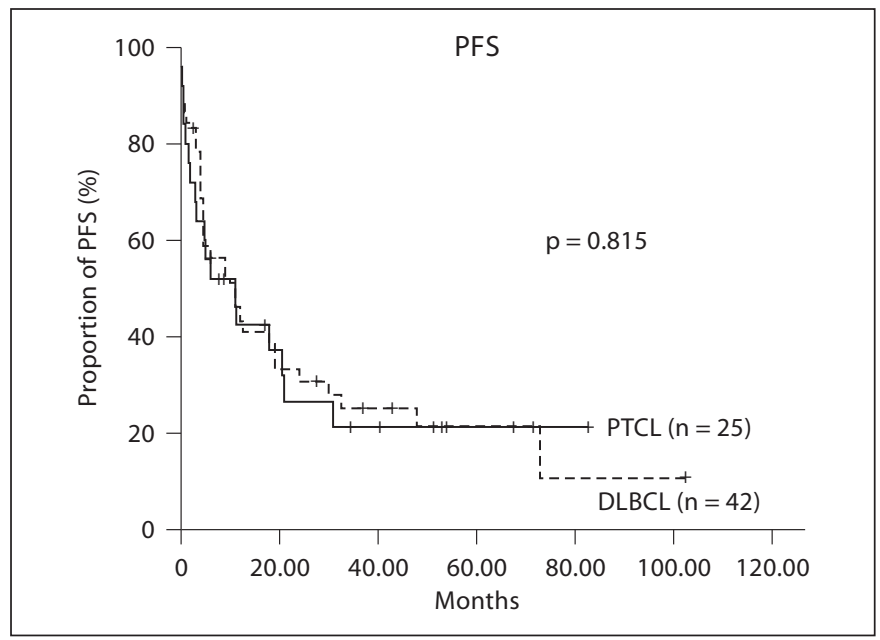

Fig. 2. PFS curves of 25 PTCL patients with BMI and 42 DLBCL patients with BMI. No difference was found between the 2 groups $(\mathrm{p}=0.815)$.

Table 3. Risk factors for PFS in 67 patients

\begin{tabular}{|c|c|c|c|}
\hline Variables & $\begin{array}{l}\text { Uni- } \\
\text { variate } \\
\mathrm{p}^{\mathrm{a}}\end{array}$ & $\begin{array}{l}\text { Multi- } \\
\text { variate } \\
\mathrm{p}^{\mathrm{b}}\end{array}$ & $\begin{array}{l}\mathrm{RR} \\
(95 \% \mathrm{CI})\end{array}$ \\
\hline Age ( $>60$ vs. $\leq 60$ years) & 0.600 & & \\
\hline Gender (male vs. female) & 0.780 & & \\
\hline Lymphadenopathy & & & \\
\hline (present vs. absent) & 0.851 & & \\
\hline Hepatomegaly (present vs. absent) & 0.197 & & \\
\hline Splenomegaly (present vs. absent) & 0.011 & 0.262 & \\
\hline Bulky mass (present vs. absent) & 0.467 & & \\
\hline ECOG PS (0-1 vs. $2-4)$ & 0.089 & & \\
\hline No. of ENS (0-2 vs. $>2$ ) & 0.067 & & \\
\hline B symptoms (present vs. absent) & 0.325 & & \\
\hline Elevated LDH (yes vs. no) & $<0.001$ & 0.004 & \multirow[t]{4}{*}{$\begin{array}{l}11.3 \\
(2.2-59.1\end{array}$} \\
\hline Hemoglobin $(<11$ g/dl vs. $\geq 11$ g/dl $)$ & 0.030 & 0.112 & \\
\hline $\operatorname{PLT}\left(<100 \times 10^{9} / \mathrm{l}\right.$ vs. $\left.\geq 100 \times 10^{9} / \mathrm{l}\right)$ & 0.003 & 0.215 & \\
\hline WBC $\left(>10 \times 10^{9} / 1\right.$ vs. $\left.\leq 10 \times 10^{9} / 1\right)$ & 0.040 & 0.612 & \\
\hline
\end{tabular}

Multivariate analysis was carried out based on factors that were positive in univariate analysis. $\mathrm{RR}=$ Relative risk; $\mathrm{CI}=$ confidence interval. ${ }^{a}$ Logrank test. ${ }^{\mathrm{b}}$ Cox regression analysis.

spread dissemination and aggressive behavior. In $\mathrm{T}$ cell NHL, the frequency of BMI on initial diagnosis was 20$40 \%$ [8], and it was as high as $90.7 \%(42 / 54)$ in China [19]. However, the different frequencies of BMI may be associated with the different constituent ratios of subtypes at different research centers. Because of the rarity of their inci- 
dence, the characteristics and outcomes of PTCL with BMI have not been well characterized. In this report, PTCL with BMI mostly occurred in young (median age 39 years) males $(68 \%)$ and most of these patients had lymphadenopathy (88\%), splenomegaly (60\%), B symptoms (76\%), elevated LDH levels (68\%), anemia (64\%), and poor PS (52\%). Recently, Tang, et al. [20] from another Chinese institution reported a similar age range of disease onset (median age 42 years) and similar incidences of male-to-female ratio (64.2\%), splenomegaly (67\%), B symptoms (73\%), elevated LDH levels (72\%), and anemia (51\%) in PTCL patients with BMI, but a lower incidence of lymphadenopathy (40\%). The very poor survival of PTCL patients with BMI, with a median OS of 14.7 months, in the current study also correlates with the results of Tong et al. [20] (median OS 12 months). The common clinical characteristics from this study and the results of the study by Tang et al. [20] may reflect the unique features of PTCL with BMI in China.

Because of the rarity of PTCL and the relatively poor understanding of the clinical and biologic characteristics of these diseases, a comparison with a better-understood counterpart B cell lymphoma has always been carried out when studying PTCL. The obtained results, however, have been contradictory. Early studies by groups from Taiwan [12] and Stanford [21] revealed that there were considerable similarities between PTCL and DLBCL in terms of clinical stage, PS, ENS involvement, LDH level, and age distribution. Based on these studies, the survival of these lymphomas was also comparable [21], especially for the advanced-stage diseases [12, 21]. However, 2 more recent studies $[7,22]$ indicated that elevated $\mathrm{LDH}$ levels, poor PS, advanced stage, and B symptoms were observed more frequently in patients with PTCL than in patients with DLBCL, while a bulky mass was observed more frequently in patients with DLBCL. The survival of PTCL patients in both studies was also inferior to that of DLBCL patients. The difference between these studies might be explained by the different cases included and the sample size because the early studies included all subtypes of PTCL as 1 entity instead of individual subtypes of PTCL $[12,21]$. Some ALK + ALCL patients might be included with a much improved survival in the PTCL group [17]. Some more recent investigations [7, 22] have directly compared non-ALCL nodal PTCL (AITL and/or PTCL-u) with DLBCL. Therefore, the conclusions from these recent studies $[7,22]$ might be more reliable.

As we know, both PTCL with BMI and DLBCL with BMI have poorer survival than those without BMI $[8,9]$, but the clinical characteristics and survival of these lymphomas have not been directly compared. Here, we per- formed the comparison between 25 PTCL patients with BMI and 42 DLBCL patients with BMI, excluding ALCL patients. Most of the clinical characteristics which were considered to have an impact on the prognosis of aggressive lymphoma, such as age, LDH level, ECOG scores, ENS involved, B symptoms, IPI, and aaIPI, were distributed equally between these 2 lymphomas. There was a significantly higher proportion (88.0\%) of patients with lymphadenopathy at diagnosis in the PTCL group and a higher proportion $(57.1 \%)$ of patients with a PLT $<100 \times$ $10^{9} / 1$ in DLBCL group. The survival of both groups was similarly poor, with 3 -year OS rates of 30.0 and $25.2 \%$ in the DLBCL and PTCL groups, respectively, but with no statistically significantly differences identified.

Immunophenotype has been generally regarded as a prognostic factor in patients with $\mathrm{T}$ cell or B cell lymphoid malignancies $[5,6,11,23,24]$. However, contradictory results have been obtained and few clinical trials have assessed whether the immunophenotype itself leads to poor outcomes and resistance to treatments. In recent literatures, the $\mathrm{T}$ cell immunophenotype itself was not reported to have had an impact on the response to conventional chemotherapy, PFS, or OS [7, 22]. The poor prognosis in patients with PTCL was shown to be associated with initial clinical factors, such as poor scores on the IPI, rather than the immunophenotype itself $[7,22$, 25]. In the current study, although lymphadenopathy at diagnosis and thrombocytopenia seem to be distributed in an unbalanced way between PTCL with BMI and DLBCL with BMI, neither factor appears to influence PFS and OS. Since the survivals between these 2 conditions are comparable, we assume that the immunophenotype of either T or B cell lineage does not have an impact on the prognosis of these 2 aggressive lymphomas.

In summary, although our study was retrospective in design and included a relatively small number of patients, DLBCL patients with BMI and PTCL patients with BMI showed comparable clinical characteristics, including IPI parameters. We have demonstrated that survival between the 2 groups was similar, implying that the immunophenotype alone may not be as critical a prognostic indicator of survival in aggressive lymphomas with BMI as currently believed.

\section{Acknowledgments}

This study was supported by grants from the Ministry of Public Health, People's Republic of China (Clinic Key Project 20072009), and the Key Project of Tianjin Science and Technology Supporting Program (09ZCGYSF01000 and 09ZCZDSF03800). 


\section{References}

1 Jaffe ES, Harris NL, Stein H, Vardiman J: Tumours of haematopoietic and lymphoid tissues: pathology and genetics. World Health Organization classification of tumours. Lyon, IARC Press, 2001.

$\checkmark 2$ Kim K, Kim WS, Jung CW, Im YH, Kang WK, Lee MH, Park CH, Ko YH, Ree HJ, Park $\mathrm{K}$ : Clinical features of peripheral T-cell lymphomas in 78 patients diagnosed according to the revised European-American lymphoma (real) classification. Eur J Cancer 2002; 38:75-81.

$\checkmark 3$ Arrowsmith ER, Macon WR, Kinney MC, Stein RS, Goodman SA, Morgan DS, Flexner JM, Cousar JB, Jagasia MH, McCurley TL, Greer JP: Peripheral T-cell lymphomas: Clinical features and prognostic factors of 92 cases defined by the revised European American lymphoma classification. Leuk Lymphoma 2003;44:241-249.

-4 Rudiger T, Weisenburger DD, Anderson JR, Armitage JO, Diebold J, MacLennan KA, Nathwani BN, Ullrich F, Muller-Hermelink HK: Peripheral T-cell lymphoma (excluding anaplastic large-cell lymphoma): Results from the Non-Hodgkin's Lymphoma Classification Project. Ann Oncol 2002;13:140 149.

5 Melnyk A, Rodriguez A, Pugh WC, Cabannillas F: Evaluation of the revised EuropeanAmerican lymphoma classification confirms the clinical relevance of immunophenotype in 560 cases of aggressive nonHodgkin's lymphoma. Blood 1997;89:45144520.

-6 Gisselbrecht C, Gaulard P, Lepage E, Coiffier B, Briere J, Haioun C, Cazals-Hatem D, Bosly A, Xerri L, Tilly H, Berger F, Bouhabdallah R, Diebold J: Prognostic significance of Tcell phenotype in aggressive non-Hodgkin's lymphomas - Groupe d'Etudes des Lymphomes de l'Adulte (GELA). Blood 1998;92: 76-82.

-7 Tomita N, Motomura S, Hyo R, Takasaki H, Takemura S, Taguchi J, Fujisawa S, Ogawa K, Ishigatsubo Y, Takeuchi K: Comparison of peripheral T-cell lymphomas and diffuse large B-cell lymphoma. Cancer 2007;109: 1146-1151.

$>8$ Gallamini A, Stelitano C, Calvi R, Bellei M, Mattei D, Vitolo U, Morabito F, Martelli M, Brusamolino E, Iannitto E, Zaja F, Cortelazzo S, Rigacci L, Devizzi L, Todeschini G, Santini G, Brugiatelli M, Federico M: Peripheral T-cell lymphoma unspecified (PTCL-u): a new prognostic model from a retrospective multicentric clinical study. Blood 2004;103: 2474-2479. $\checkmark 9$ Chung R, Lai R, Wei P, Lee J, Hanson J, Belch AR, Turner AR, Reiman T: Concordant but not discordant bone marrow involvement in diffuse large B-cell lymphoma predicts a poor clinical outcome independent of the International Prognostic Index. Blood 2007; 110:1278-1282.

10 Thiele J, Zirbes TK, Kvasnicka HM, Fischer R: Focal lymphoid aggregates (nodules) in bone marrow biopsies: differentiation between benign hyperplasia and malignan lymphoma - a practical guideline. J Clin Pathol 1999;52:294-300.

11 A clinical evaluation of the International Lymphoma Study Group classification of non-Hodgkin's lymphoma: the non-Hodgkin's lymphoma classification project. Blood 1997;89:3909-3918.

12 Cheng AL, Chen YC, Wang CH, Su IJ, Hsieh HC, Chang JY, Hwang WS, Su WC, Liu TW, Tien HF, Tsai W, Shen MC, Liu CH: Direct comparisons of peripheral T-cell lymphoma with diffuse B-cell lymphoma of comparable histological grades - should peripheral $\mathrm{T}$ cell lymphoma be considered separately? J Clin Oncol 1989;7:725-731.

13 The World Health Organization classification of malignant lymphomas in Japan: incidence of recently recognized entities. Lymphoma study group of Japanese pathologists. Pathol Int 2000;50:696-702.

14 Arber DA, George TI: Bone marrow biopsy involvement by non-Hodgkin's lymphoma: frequency of lymphoma types, patterns, blood involvement, and discordance with other sites in 450 specimens. Am J Surg Pathol 2005;29:1549-1557.

15 Conlan MG, Bast M, Armitage JO, Weisenburger DD: Bone marrow involvement by non-Hodgkin's lymphoma: the clinical significance of morphologic discordance between the lymph node and bone marrow. $\mathrm{Ne}$ braska Lymphoma Study Group. J Clin Oncol 1990;8:1163-1172.

16 Ansell SM, Habermann TM, Kurtin PJ, Witzig TE, Chen MG, Li CY, Inwards DJ, Colgan JP: Predictive capacity of the International Prognostic Factor Index in patients with peripheral T-cell lymphoma. J Clin Oncol 1997 15:2296-2301.

17 Armitage JO, Vose JM, Weisenburger DD: Towards understanding the peripheral T-cell lymphomas. Ann Oncol 2004;15:1447-1449.
18 Cheson BD, Horning SJ, Coiffier B, Shipp MA, Fisher RI, Connors JM, Lister TA, Vose J, Grillo-Lopez A, Hagenbeek A, Cabanillas F, Klippensten D, Hiddemann W, Castellino R, Harris NL, Armitage JO, Carter W, Hoppe R, Canellos GP: Report of an international workshop to standardize response criteria for non-Hodgkin's lymphomas - NCI Sponsored International Working Group. J Clin Oncol 1999; 17:1244.

19 Yuan XL, Li QC, Zou DH, Zhao YZ, Wang YF, Wang Y, Zhang JW, Qiu LG: Retrospective analysis of 54 patients with high risk aggressive T-cell non-Hodgkin lymphomas (in Chinese). Zhonghua Xue Ye Xue Za Zhi 2007;28:454-457.

>20 Tong H, Ren Y, Qian W, Xiao F, Mai W, Meng $\mathrm{H}$, Jin J: Clinicopathological study on peripheral T-cell non-Hodgkin lymphoma with bone marrow involvement: a retrospective analysis from China. Int J Hematol 2009; 90:303-310.

21 Kwak LW, Wilson M, Weiss LM, Doggett R, Dorfman RF, Warnke RA, Horning SJ: Similar outcome of treatment of B-cell and T-cell diffuse large-cell lymphomas: the Stanford experience. J Clin Oncol 1991;9:1426-1431.

22 Morabito F, Gallamini A, Stelitano C, Callea V, Guglielmi C, Neri S, Lazzaro A, Orsucci L, Ilariucci F, Sacchi S, Vitolo U, Federico M: Clinical relevance of immunophenotype in a retrospective comparative study of 297 peripheral T-cell lymphomas, unspecified, and 496 diffuse large b-cell lymphomas: experience of the Intergruppo Italiano Linformi. Cancer 2004;101:1601-1608.

$\checkmark 23$ Coiffier B, Brousse N, Peuchmaur M, Berger F, Gisselbrecht C, Bryon PA, Diebold J: Peripheral T-cell lymphomas have a worse prognosis than B-cell lymphomas: a prospective study of 361 immunophenotyped patients treated with the LNH-84 regimen. The GELA (Groupe d'Etude des Lymphomes Agressives). Ann Oncol 1990;1:45-50.

24 Lee SS, Cho KJ, Kim CW, Kang YK: Clinicopathological analysis of 501 non-Hodgkin's lymphomas in Korea according to the revised European-American classification of lymphoid neoplasms. Histopathology 1999; 35:345-354.

25 Sohn BS, Park I, Kim EK, Yoon DH, Lee SS, Kang BW, Jang G, Choi YH, Kim C, Lee DH, Kim S, Huh J, Suh C: Comparison of clinical outcome after autologous stem cell transplantation between patients with peripheral T-cell lymphomas and diffuse large B-cell lymphoma. Bone Marrow Transplant 2009; 44:287-293. 